\title{
Comparing Effectiveness of Standard vs HF10 Spinal Cord Stimulator Implants for Chronic Intractable PaIn
}

\author{
Manasi Parikh, MS 1 \\ Ashish Bhandari, MBBS2 \\ Christopher Gilligan, MD²
}

Background: There is limited real-world evidence regarding the long-term effectiveness and safety outcomes related to spinal cord stimulation (SCS) for patients with chronic refractory pain.

Case Report: This study included a total of 132 patients (73 had HF10); $53 \%$ was female. Mean Pretrial Numeric Pain Score for all patients was $8.4 \pm 1.1$ which decreased to $4.4 \pm 2.0$ at the end of one year $(P<0.0001)$. A $6 \%$ decrease in the percent of responders, between one month and one-year post-implant, was noted in the HF10 SCS compared to the $15 \%$ in standard SCS. A statistically significant decrease in pain relief in the male population $(P=0.02)$ and obese patients $(P=0.002)$ was observed. Most common complications: "IPG malfunction" (17\%) for standard SCS and "IPG site pain" (12\%) for HF10 SCS.

Conclusion: HF10 SCS is a viable alternative to standard SCS for chronic intractable pain conditions.

Key words: Complications, HF10, high-frequency stimulation, neuromodulation, patient outcomes, spinal cord stimulation

\section{BACKGROUND}

Chronic pain is a multidimensional health condition defined by the International Association for the Study of Pain (IASP) as pain persisting for more than 6 months (1); it affects $22 \%$ of the world population according to a multicenter study conducted by the World Health Organization (WHO) (2). Spinal cord stimulation (SCS) has become a viable treatment option for patients with chronic pain $(3,4)$. SCS patients report greater improvements in pain, quality of life, and activity levels, and have a higher return-to-work rate than those receiving conservative treatment such as pharmacological treatment, physical therapy, epidural injections, and/or radiofrequency therapy (5-7). One important advantage of this intervention is its success in treating chronic non- malignant pain conditions that previously had limited surgical or pharmacological solutions aside from opioid therapy (8). It is important to report on SCS efficacy over time, given the increasing popularity of this treatment, the initial high costs associated with it, and the expanding range of indications for its use $(7,9)$. Continuous evaluation regarding patient outcomes in terms of pain control, any complications, and overall satisfaction is important in determining SCS's role in clinical practice.

Conventional SCS devices use electrical stimulation, which typically ranges between tens to hundreds of hertz $(\mathrm{Hz})$, and patients perceive nonpainful paresthesia (a stimulation-induced sensation, such as tingling or buzzing) in lieu of otherwise painful sensations. However, standard SCS therapy poses some limita-

From: ${ }^{1}$ Graduate Medical Sciences, Boston University School of Medicine, Boston University, Boston, MA; ${ }^{2}$ Department of Anesthesiology, Perioperative and Pain Medicine, Brigham \& Women's Hospital, Boston, MA 
tions due to the side effects of paresthesia, such as unintended, unwanted, or painful stimulation, or stimulation shocks because of change in body position $(3,10,11)$. In contrast, the recent clinical use of highfrequency SCS at $10 \mathrm{kHz}$ (HF10 ${ }^{\text {TM }}$ Therapy by Nevro's Senza SCS system, Rewood City, CA) represents novel neurostimulation therapy. HF10 therapy is the only SCS therapy indicated to provide pain relief without paresthesia and is also the first SCS therapy to demonstrate superiority to traditional SCS for back and leg pain in a few studies (12-15).

However, there is scarce real-world evidence outside controlled study settings in the research literature regarding the use of HF10 SCS. Clinically, there is a lack of high-quality randomized trials with HF10 SCS and, as noted by Song et al (8) in their review, large randomized controlled trials demonstrating clear clinical benefit are needed to gain evidence-based support for their use. Studies have demonstrated the efficacy of SCS using endpoints of pain control as measured by patientreported pain scores, opioid use, and patient satisfaction (16-18). Despite the vast literature on SCS as a treatment option, there is a relative paucity of literature regarding the correlation between basic demographic data and SCS therapy outcomes.

Currently, there is ambiguity in the literature regarding long-term effectiveness and safety outcomes related to SCS especially given the continuous evolving technology in the field. It is necessary to identify patient outcomes in terms of pain control, demographic data, and overall satisfaction to best classify SCS's role in the pain treatment algorithm and to improve patient education prior to implantation. This study is a comprehensive analysis of patients from one academic center who underwent an SCS implant, with the following objectives: a) describe and compare patient outcomes among patients who underwent standard SCS vs HF10 SCS therapy for treatment of chronic pain in routine clinical practice; b) evaluate any associations between outcomes and basic demographic variables such as age, gender, and weight; and c) identify contemporary incidence of treatment-limiting complications, defined as those requiring a revision or explant.

\section{METHODS}

This study was a retrospective, observational analysis of 132 patients who underwent an SCS implant over a 2-year period between September 2015 and September 2017 at Brigham and Women Hospital's
Pain Center. We compared patient outcomes on traditional/standard SCS devices (like Medtronic and Boston Scientific) to the HF10 SCS system (Nevro's Senza SCS system). The academic center has experience in traditional SCS devices as well as the HF10 SCS system since the latter therapy received Food and Drug Administration (FDA) approval in May 2015. Institutional Review Board approval was obtained prior to beginning this study.

\section{Study Population and Patient Selection}

All consecutive adult patients diagnosed with a chronic pain condition who underwent permanent, primary cervical or thoracolumbar SCS implantation between September 2015 and September 2017 were included in this study. Patients who had a previous history of SCS implantation and who underwent peripheral nerve stimulation implants at any time during the study period were excluded in this study analysis. Patients were deemed suitable for SCS therapy per physicians' opinion and psychological evaluation.

\section{Procedures and Follow-Up}

All patients included in this study had undergone a successful SCS trial prior to implantation and the surgical implant procedure was conducted according to the established standard of care. A 5- to 7-day outpatient trial with an external SCS device was done to determine clinical efficacy. A trial was considered successful if $>50 \%$ pain relief was achieved without any adverse effects. After a successful trial, patients proceeded to a permanent SCS implant as a day surgery procedure. The HF10 SCS surgical procedure differs from that used for standard SCS in 3 key technical ways: 1) the 2 leads were sited solely anatomically along the spinal vertebrae; 2 ) concordant paresthesia-mapping was not performed at any time; and 3) there was no need to lighten sedation for paresthesia testing (15). A programming algorithm was used to optimize the SCS stimulation according to each patient's report of pain relief. Each device was programmed with the aid of a device manufacturer representative to ensure adequate pain relief according to the individual patient's pain distribution. After implantation, follow-up consisted of an initial postoperation visit within 7 days of surgery. This was followed by a one-month visit and then visits as needed for any programming adjustments or complication issues. Changes in pain medications based on clinical judg- 
ment and adjustment of stimulation parameters were made throughout the follow-up period. Also, patients could adjust the amplitude of the therapy, within a predefined range, using a patient remote control. Follow-up data was collected through August 2018, allowing for a minimum follow-up time of 12 months since implant or until device explant.

\section{Data Collection}

Patients' baseline, preimplant, and postimplant data were retrieved retrospectively from the site's electronic medical record system. For each patient, the following demographic information was recorded at baseline: age at the time of implantation, gender, body mass index (BMI) at the time of implantation, and date of implantation. SCS vendors included Boston Scientific, Medtronic, and Nevro. Preimplant information included a) indication for implantation, b) percent pain relief during SCS trial, and c) Numeric Pain Score (NPS) (which ranges from 0-10) prior to implant. The NPS was noted from the most recent clinical note prior to implantation. Postimplant information consisted of a) NPS assessed at one month, 6 months, and 12 months post implant as available in the medical records; b) patient satisfaction, determined based on clinical documentation (a patient was recorded as "satisfied" if he or she stated being happy with his or her SCS and felt that undergoing the implantation had improved pain control); c) explant or revision of SCS at any time during the study period and the underlying cause of it; and d) complications related to SCS as reported in the chart during the study period.

\section{Statistical Analysis}

The data was entered in Microsoft Excel (Seattle, WA) and analyzed using R Version 3.5.1 (The R foundation for Statistical Computing Platform, Vienna, Austria). Descriptive statistics were calculated for each analyzed variable and consisted of frequencies, means, percentages, and standard deviation. Two-tailed paired t tests were used to analyze change in the mean percent pain relief as well as change in NPS over time within the same group. The $t$ test (2-tailed) was also used to analyze the statistical significance of the differences in mean percent pain relief among different subgroups. Additionally, the one-way analysis of variance (ANOVA) test was used to compare the mean percent pain relief in the $3 \mathrm{BMI}$ subgroups. A $P$ value $<.05$ was considered as statistically significant.

\section{RESULTS}

\section{Baseline}

A total of 132 patients underwent implant; $47 \%$ were men and 53\% women. Out of 132, 73 had HF10 SCS implantation, which includes $55 \%$ of the total study population. The mean age was 55.6 years. The mean pretrial NPS for all patients was $8.4 \pm 1.1$ and $50 \%$ of the study population fell within the NPS 8-9 range at baseline. According to BMI, patients were further categorized into the following: normal (24\%), overweight $(35 \%)$, and obese (33\%). The most common chronic pain condition indication seen in the study population included postlaminectomy syndrome (PLS) (62\%), lumbar radiculopathy (LR) or cervical radiculopathy (CR) (12\%), and chronic regional pain syndrome (CRPS) (7\%). Overall, $79.5 \%$ of the study population was satisfied with SCS therapy. Of the patients with HF10 SCS, 80.2\% were satisfied compared to $81.3 \%$ on standard SCS. A summary of baseline information as well as follow-up is presented in Table 1 and Appendix Fig. 1, respectively.

\section{Pain Score and Percent Changes in Pain Relief}

At one year, the mean reported NPS score for whole study population was $4.9 \pm 2.1$, compared with $4.7 \pm$ 2.0 at one month and $4.7 \pm 2.9$ at 6 months (Table 2). Pain reductions for these patients were statistically significant at one month, 6 months, and one year post implant $(P<.001)$. This study shows that the pain relief afforded by SCS is maintained for at least 12 months. The mean percent pain relief during the trial for the study population was $68 \%$, which declined to $41 \%$ at the end of one year in the same patient cohort (Fig. $1)$. The mean percent pain relief was slightly better with standard SCS (70\% to $44 \% ; P=.30)$ compared to HF10 (67\% to $40 \% ; P=.56)$ over time. As shown in Fig. 2 , the mean percent pain relief did not differ much among age groups at the end of one year. In terms of gender, mean percent pain relief was greater among women (43\%) compared to men (38\%) at one year post implant. Moreover, the decrease in mean percent pain relief for men at one month (44\%) as compared to one year $(38 \%)$ is statistically significant $(P=.02)$. The mean percent pain relief increased for normal ( $40 \%$ to $43 \%$; $P=.73)$ and overweight patients (43\% to $44 \% ; P=.69)$ with time; however, for obese patients it decreased with time $(47 \%$ to $36 \%)$. In the obese subgroup of patients, the reduction in mean percent pain relief over time was statistically significant $(P=.002)$ (Appendix Table 1 and Table 2). 
Table 1. Demographics and baseline information of the study population.

\begin{tabular}{|c|c|}
\hline Variable & $\mathbf{n}$ \\
\hline Total & 132 \\
\hline \multicolumn{2}{|l|}{ Gender $(\%)$} \\
\hline Men & $62(47 \%)$ \\
\hline Women & $70(53 \%)$ \\
\hline \multicolumn{2}{|l|}{ SCS Therapy (\%) } \\
\hline Standard & $59(45 \%)$ \\
\hline HF10 & $73(55 \%)$ \\
\hline Complications (\%) & $41(32 \%)$ \\
\hline Revisions (\%) & $24(18 \%)$ \\
\hline Explants (\%) & $18(14 \%)$ \\
\hline \multicolumn{2}{|l|}{ Indications (\%) } \\
\hline Chronic Regional Pain (CRPS) & $10(7 \%)$ \\
\hline Failed Back Surgery Syndrome (FBSS) & $6(4 \%)$ \\
\hline $\begin{array}{l}\text { Lumbar Radiculopathy (LR)/Cervical } \\
\text { Radiculopathy (CR) }\end{array}$ & $16(12 \%)$ \\
\hline Post Laminectomy Syndrome (PLS) & $82(62 \%)$ \\
\hline Neuralgia & $8(6 \%)$ \\
\hline $\begin{array}{l}\text { OTHER (e.g., Central Pain Syndrome, Chronic } \\
\text { angina, fibromyalgia) }\end{array}$ & $10(7 \%)$ \\
\hline Mean Age (SD) & $55.6(13.2)$ \\
\hline Mean BMI (SD) & $29.2(7.1)$ \\
\hline Normal (18.5-24.9) & $29.2(7.1)$ \\
\hline Overweight (25.0-29) & $46(35 \%)$ \\
\hline Obesity $(>30.0)$ & $44(33 \%)$ \\
\hline
\end{tabular}

Abbreviations: BMI, body mass index; SCS, spinal cord stimulation; SD, standard deviation

\section{Percentage of Responders}

It is important to elaborate more on the percentage of responders (patients getting more than or equal to $50 \%$ pain relief with respect to baseline pain) to better understand the therapeutic effect. During the trial, $82 \%$ of the study population reported a $50 \%$ or more reduction in NPS. However, at one month, responders represented $44 \%$ of the study population, followed by $40 \%$ and $33 \%$ at 6 months and one year, respectively. Thus, in this study cohort, the percentage of patients getting more than $50 \%$ pain relief decreased by $11 \%$ at one year as compared to one month (Fig. 3). Only a $6 \%$ decrease in the percentage of pain responders was seen in the HF10 SCS group compared to the $15 \%$ decrease in the standard SCS group, from one month to one year post implant. There was an almost equal decrease in percentage of responders in men and women. Moreover, a greater
Table 2. NPS changes in the study cohort over time.

\begin{tabular}{|l|c|c|c|c|}
\hline Time & Baseline & $\mathbf{1 ~ m o}$ & $\mathbf{6 ~ m o s}$ & $\mathbf{1 ~ y}$ \\
\hline $\mathrm{n}$ & 132 & 129 & 114 & 97 \\
\hline Mean NPS & 8.4 & 4.7 & 4.7 & 4.9 \\
\hline $\begin{array}{l}\text { Standard } \\
\text { Deviation (SD) }\end{array}$ & 1.11 & 1.98 & 2.08 & 2.05 \\
\hline $\begin{array}{l}\text { Standard Error } \\
\text { Mean (SEM) }\end{array}$ & 0.09 & 0.17 & 0.19 & 0.20 \\
\hline$P$ value & & $<.001$ & $<.001$ & $<.001$ \\
\hline $\begin{array}{l}\text { 95\% Confidence } \\
\text { Interval }\end{array}$ & & $\begin{array}{c}3.34 \\
-4.05\end{array}$ & $\begin{array}{c}3.20 \\
-4.09\end{array}$ & $\begin{array}{c}3.05 \\
-3.99\end{array}$ \\
\hline
\end{tabular}

Abbreviations: NPS, Numeric Pain Score

decrease in the percentage of responders among patients less than 56 years of age was also noted over time. An interesting observation was that of an increase in the percentage of responders in the normal and overweight subgroups between one month and one year post implant. However, in obese patients, there was a substantial decrease in the percentage of responders, from $52 \%$ at one month to $29 \%$ at one year post implant (Fig. 4).

\section{Complications}

A total of 41 cases of complications were reported among the 132 patients in the study, and sometimes patients experienced more than one complication" (Table 3). "Inadequate pai relief" (described as tolerance or loss of therapeutic effect despite appropriate stimulation coverage that cannot be explained by a hardware-related issue) along with "implantable pulse generator (IPG) site pain" were the most common complications associated with the HF10 SCS system, seen in $23 \%$ of cases. "SCS malfunction" (17\%) was most commonly associated with standard SCS devices. SCS system malfunction involves either of the following: lead migration, lead defect/fracture, or IPG battery issue or other hardware-related complication. It was noted that such hardware-related complications were more common than biologic complications and a prominent issue with SCS that required revisions. Inadequate pain relief was seen in 13 patients (10\%) and accounted for $76 \%$ of explants.

\section{Revisions and Explants}

There were 24 revisions and 18 explants in 132 patients, for a revision rate and explant rate of $18 \%$ and $14 \%$, respectively. Indications for revision in order of decreasing frequency included IPG site pain, SCS system 
malfunction (involving either leads migration/defect or IPG battery issue), and loss of therapeutic effect/ inadequate pain relief. Indications for explant in this patient population, in order of decreasing frequency, included loss of therapeutic effect, IPG discomfort/site pain, and SCS malfunction related to migration, IPG battery defect, etc. As shown in Appendix Fig. 2, the device retention rate was $53 \%$ at the end of 3 years, which included all those patients who continuously used the SCS device and hadn't yet undergone a revision or explant.

\section{DISCUSSION}

This study demonstrates the effectiveness of SCS therapy in a challenging clinical patient cohort and demonstrates significant improvements in pain and patient satisfaction. The results signify a promising therapeutic option for patients suffering from a range of chronic intractable pain conditions who have previously failed conservative treatment. Efficacy of traditional lowfrequency SCS may diminish with time, as seen in this study as well as other studies in the literature $(7,19)$. It is essential to evaluate any new SCS modality over a longer term. Additionally, this is one of the few studies to provide 12-month follow-up information related to efficacy, patient satisfaction, and safety data of patients who have undergone a HF10 SCS implant. Other strengths of the study include the fact that it is one of the few studies to assess the association of sociodemographic characteristics with pain outcomes in SCS patients, its sizeable study group for the new SCS modality (73 patients receiving permanent HF10 SCS implant), and a high follow-up percentage of $86 \%$ (63 of 73) at 12 months for the HF10 subgroup of patients.

\section{Pain Score Outcomes}

Pain significantly declined, as seen by the NPS at 6- and 12-months post implant, whether observing all patients or patient subgroups based on age, gender, therapy, and BMI. The results of this study are similar to several other clinical studies $(9,13,15)$. The average NPS scores decreased by more than $50 \%$ in $82 \%$ of the study population during the trial, which was sustained by only $33 \%$ of the total study population at one year. The percentage of responders was similar among both the HF10 and traditional SCS therapy patients at the end of one year. The results in this study add to the evidence that the benefits of SCS diminish over time. According to the chart review of the study population,

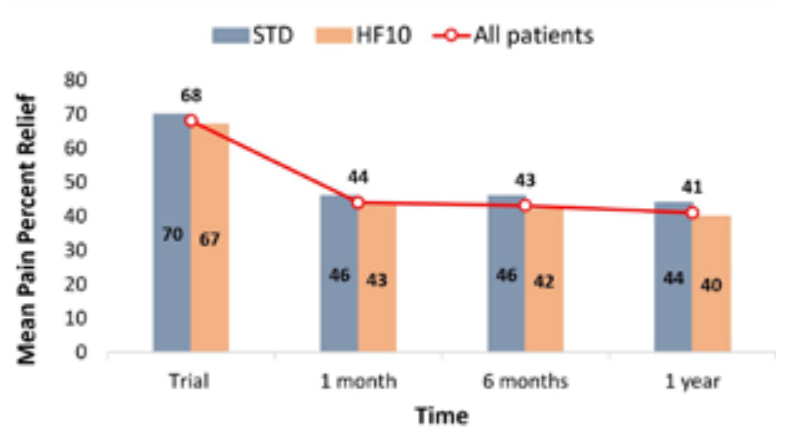

Fig 1. Mean percent pain relief (PPR) between the 2 types of SCS therapy and overall study population over time.

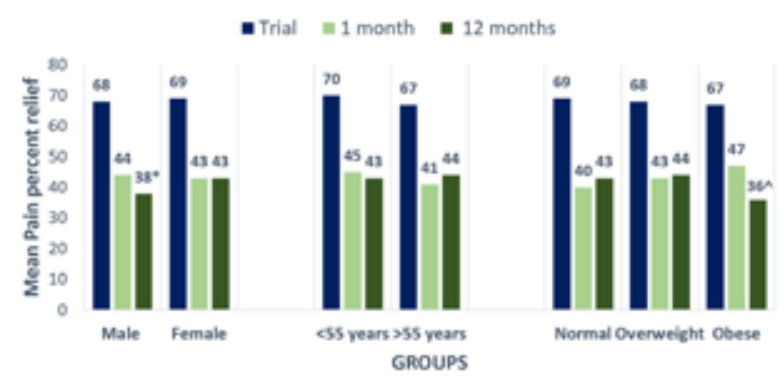

Fig 2. Comparing mean percent pain relief (PPR) at 1 month and 1 year within a group.

*the decrease in mean PPR for male population at one month (44\%) as compared to one year (38\%) is statistically significant $(P=.02)$

$\wedge$ In obese patients decrease in Mean PPR with time is statistically significant $(P=.002)$.

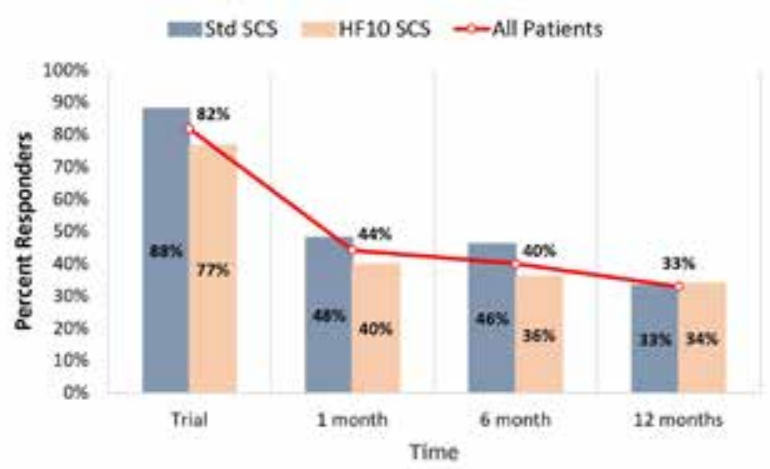

Fig 3. Percent responders* across time in the study population and according to the SCS therapy.

* patients getting more than or equal to $50 \%$ pain relief with respect to baseline pain. 


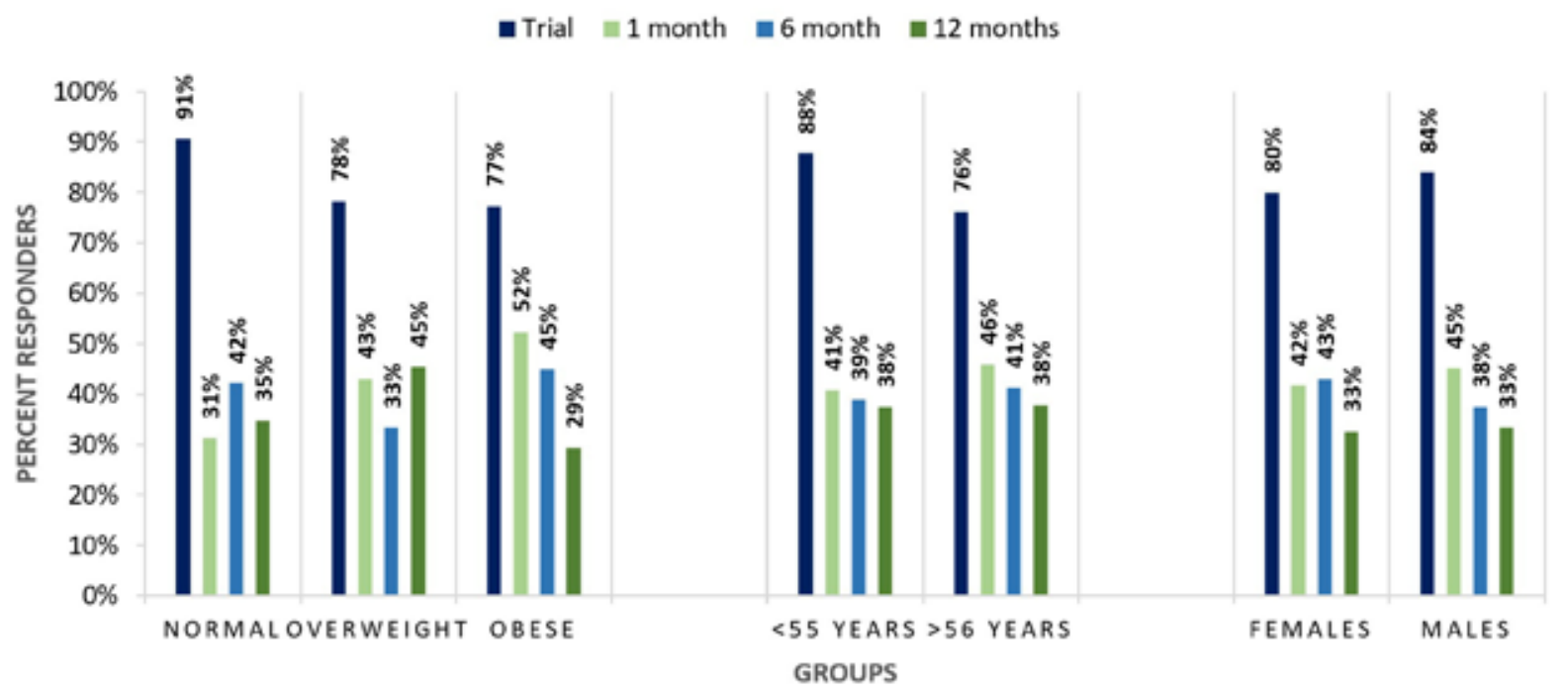

Fig 4. Percent responders* across time according to demographic groups.

* patients getting more than or equal to $50 \%$ pain relief with respect to baseline pain

Table 3. Summary of complications related to SCS in the study population.

\begin{tabular}{|l|c|c|c|}
\hline \multirow{2}{*}{ Complications } & \multicolumn{3}{|c|}{ No. of Cases } \\
\cline { 2 - 4 } & $\begin{array}{c}\text { STD } \\
(\mathbf{n}=\mathbf{5 9})\end{array}$ & $\begin{array}{c}\text { HF10 } \\
(\mathbf{n}=\mathbf{7 3})\end{array}$ & $\begin{array}{c}\text { Total } \\
(\mathbf{n}=\mathbf{1 3 2})\end{array}$ \\
\hline IPG site pain & $4(7 \%)$ & $9(12 \%)$ & $13(10 \%)$ \\
\hline SCS malfunction & $10(17 \%)$ & $2(3 \%)$ & $12(9 \%)$ \\
\hline Inadequate pain relief & $5(8 \%)$ & $8(11 \%)$ & $13(10 \%)$ \\
\hline Infection & $2(3 \%)$ & $1(1 \%)$ & $3(2 \%)$ \\
\hline
\end{tabular}

Abbreviations: IPG, implantable pulse generator; SCS, spinal cord stimulation; STD, standard SCS

the following reasons may be responsible for lack of significant pain relief: confounding pathology (new and/or old), progression of disease, patients reframing their pain, low pretrial NPS scores, trial success based on benefits other than pain, device troubleshooting and programming issues, and infection.

Interesting results were observed when mean percent pain relief was compared among various subgroups based on sociodemographic characteristics. In the normal and overweight subgroups of patients, the mean percent pain relief as well as the percentage of responders increased with time. Statistically significant decreases in pain relief over time among men and in the obese subgroup of patients were observed. There is a possibility that SCS therapy is not advisable for these 2 subgroups in the long run as treatment efficacy reduces with time and thus SCS may not prove to be a cost-effective alternative compared to standard treatment in such cases. The probable causes behind this finding need further prospective research, and the associations between gender, BMI, and pain relief with SCS should be studied in greater detail with a bigger sample in a clinical trial.

\section{Traditional SCS vs. HF10 Therapy}

From this study, it can be concluded that HF10 therapy potentially demonstrates greater long-term efficacy and safety. A study by Al-Kaisy et al (15) found that using HF10 SCS in patients who have failed traditional SCS has longterm benefits. These patients had either failed an SCS trial due to the lack of back paresthesia coverage or failed after permanent IPG implant due to the loss of back pain relief. This is particularly important for many patients with current SCS systems who are not getting optimal results. One major advantage of HF10 SCS therapy is that it overcomes the paresthesia effect. It is important to further study how different HF10 SCS parameters contribute to the modulation of neural pathways responsible for nociception in order to better understand the differences in efficacy and safety of the 2 types of SCS therapies.

\section{Complications}

The complications of SCS can be many and the incidence reported in the current study population was $32 \%$, 
which is within the reported incidences of $30 \%$ to $55 \%$ in multiple studies $(5,20-22)$. But the revision and explant rates noted in this cohort were less than incidences reported in other studies (23). It is important to recognize patterns that may help the practitioner prevent, predict, and manage these complications. With the majority of explants being secondary to "inadequate pain relief" in this study cohort, further research into the identification of causative factors and development of management strategies are important to maintain the long-term efficacy of SCS. Our goal will be to identify ahead of time patients who would not get adequate relief and to avoid implanting them in the first place.

Hardware-related problems such as lead/IPG failure and migration were more common than biological complications including infection, pain, and wound breakdown. The high rates of hardware-related complications could be improved significantly with the recent advancement of SCS technology. Infection is one of the major complications of SCS and is a common cause for device removal according to previous studies. The incidence of infection was $2 \%$ in this cohort, which is less than the range of $4 \%$ to $10 \%$ published in the literature $(20-22,24,25)$. The pain center's extensive experiences in these procedures, strict sterile technique, reduction in surgical time, perioperative prophylactic antibiotic therapy, and close postoperative follow-up could be some of the reasons for minimal incidences of infection and other complications.

\section{Limitations and Future Studies}

Documentation of outcomes and patient follow-up was less rigorous in this study as compared to clinical trials, and missing data is unavoidable in a retrospective study design. A portion of patients were also lost to follow-up and could potentially bias the outcome in either a positive or negative way. For example, if a patient is doing well, they may not feel the need to attend follow-up sessions, resulting in underreporting of successful clinical outcomes; alternatively, nonresponders to treatment may not feel better and seek alternative follow-up care elsewhere. Another limitation is regarding the heterogeneity of the patient population, such as the wide range of pain distributions, underlying indications/ diagnoses, and the presence of comorbidities that may confound reported pain outcomes.

Currently, gaps exist in reporting complete information on stimulation parameters, mechanism of action of SCS devices, and safety outcomes, all of which may be improved through standardization of reporting. Furthermore, studies should report on the long-term outcomes in SCS as well as compare different types of SCS treatment modalities.

\section{CONCLUSION}

Repeated evaluation regarding patient outcomes in terms of pain control, any complications, and overall satisfaction is essential to compare and maintain different SCS therapies in clinical practice. It is important to continuously analyze efficacy of HF10 SCS therapy through postmarket "real world" studies. A statistically significant decrease in pain relief with time was observed in men and obese patients. Thus, association of long-term pain relief related to gender and obesity in SCS patients needs further investigation. The current study provides promising evidence that both modalities of SCS are viable alternatives for patients with chronic intractable pain conditions in a standard clinical practice setting. 


\section{REFERENCES}

1. Classification of chronic pain. Descriptions of chronic pain syndromes and definitions of pain terms. Prepared by the International Association for the Study of Pain, Subcommittee on Taxonomy. Pain Suppl 1986; 3:S1-S226.

2. Gureje O, Von Korff M, Simon GE, Gater R. Persistent pain and well-being: A World Health Organization study in primary care. JAMA 1998; 280:147-151.

3. Compton AK, Shah B, Hayek SM. Spinal cord stimulation: A review. Curr Pain Headache Rep 2012; 16:35-42.

4. Kunnumpurath S, Srinivasagopalan R, Vadivelu N. Spinal cord stimulation: Principles of past, present and future practice: a review. J Clin Monit Comput 2009; 23:333-339.

5. Cameron T. Safety and efficacy of spinal cord stimulation for the treatment of chronic pain: A 20-year literature review. J Neurosurg 2004; 100:254-267.

6. Kumar K, Taylor RS, Jacques L, et al. Spinal cord stimulation versus conventional medical management for neuropathic pain: A multicentre randomised controlled trial in patients with failed back surgery syndrome. Pain 2007; 132:179-188.

7. Kumar K, Taylor RS, Jacques L, et al. The effects of spinal cord stimulation in neuropathic pain are sustained: A 24-month followup of the prospective randomized controlled multicenter trial of the effectiveness of spinal cord stimulation. Neurosurgery 2008; 63:762-770; discussion 770.

8. Song JJ, Popescu A, Bell RL. Present and potential use of spinal cord stimulation to control chronic pain. Pain Physician 2014; 17:235-246.

9. Van Buyten J-P, Al-Kaisy A, Smet I, Palmisani S, Smith T. High-frequency spinal cord stimulation for the treatment of chronic back pain patients: Results of a prospective multicenter European clinical study. Neuromodulation 2013; 16:59-65; discussion 65-66.

10. Tiede J, Brown L, Gekht G, Vallejo R, Yearwood T, Morgan D. Novel spinal cord stimulation parameters in patients with predominant back pain. Neuromodulation 2013; 16:370-375.

11. Schultz DM, Webster L, Kosek P, Dar U, Tan Y, Sun M. Sensor-driven position-adaptive spinal cord stimulation for chronic pain. Pain Physician 2012; 15:1-12.

12. Kapural L, Yu C, Doust MW, et al. Comparison of 10-kHz high-frequency and traditional low-frequency spinal cord stimulation for the treatment of chronic back and leg pain: 24-month results from a multicenter, randomized, controlled pivotal trial. Neurosurgery 2016; 79:667-677.

13. Russo M, Verrills P, Mitchell B, Salmon J, Barnard A, Santarelli D. High frequency spinal cord stimulation at $10 \mathrm{kHz}$ for the treatment of chronic pain: 6-month Australian clinical experience. Pain Physician 2016; 19:267-280.
14. Kapural L, Yu C, Doust MW, et al. Novel 10-kHz high-frequency therapy (HF10 therapy) is superior to traditional low-frequency spinal cord stimulation for the treatment of chronic back and leg pain: The SENZA-RCT randomized controlled trial. Anesthesiology 2015; 123:851-860

15. Al-Kaisy A, Van Buyten J-P, Smet I, Palmisani S, Pang D, Smith T. Sustained effectiveness of $10 \mathrm{kHz}$ high-frequency spinal cord stimulation for patients with chronic, low back pain: 24-month results of a prospective multicenter study. Pain Med 2014; 15:347-354.

16. de Vos CC, Dijkstra C, Lenders MW, Holsheimer J. Spinal cord stimulation with hybrid lead relieves pain in low back and legs. Neuromodulation 2012; 15:118-123; discussion 123.

17. Kumar K, Hunter G, Demeria D. Spinal cord stimulation in treatment of chronic benign pain: Challenges in treatment planning and present status, a 22-year experience. Neurosurgery 2006; 58:481-496; discussion 481-496.

18. Barolat G, Oakley JC, Law JD, North RB, Ketcik B, Sharan A. Epidural spinal cord stimulation with a multiple electrode paddle lead is effective in treating intractable low back pain. Neuromodulation 2001; 4:59-66.

19. Kemler MA, de Vet HCW, Barendse GAM, van den Wildenberg FAJM, van Kleef M. Effect of spinal cord stimulation for chronic complex regional pain syndrome Type I: Five-year final followup of patients in a randomized controlled trial. J Neurosurg 2008; 108:292-298

20. Mekhail NA, Mathews M, Nageeb F, Guirguis M, Mekhail MN, Cheng J. Retrospective review of 707 cases of spinal cord stimulation: Indications and complications. Pain Pract 2011; 11:148-153.

21. Turner JA, Loeser JD, Deyo RA, Sanders SB. Spinal cord stimulation for patients with failed back surgery syndrome or complex regional pain syndrome: A systematic review of effectiveness and complications. Pain 2004; 108:137-147.

22. Kumar K, Wilson JR, Taylor RS, Gupta S. Complications of spinal cord stimulation, suggestions to improve outcome, and financial impact. J Neurosurg Spine 2006; 5:191-203.

23. Hayek SM, Veizi E, Hanes M. Treatment-limiting complications of percutaneous spinal cord stimulator implants: A review of eight years of experience from an academic center database. Neuromodulation 2015; 18:603-609.

24. Turner JA, Loeser JD, Bell KG. Spinal cord stimulation for chronic low back pain: A systematic literature synthesis. Neurosurgery 1995; 37:1088-1095; discussion 1095-1096.

25. Kay AD, McIntyre MD, Macrae WA, Varma TRK. Spinal cord stimulation - A long-term evaluation in patients with chronic pain. $\mathrm{Br} J$ Neurosurg 2001; 15:335-341. 


\section{TIME}

1 MONTH

\section{BASELINE}

\section{2}

PATIENTS

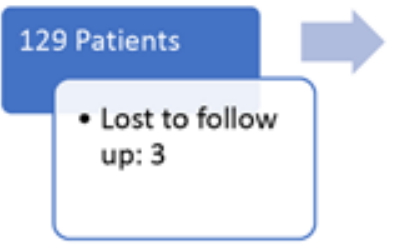

\section{MONTHS}

\section{4 patients}

- Explanted: 3

- Lost to follow up: 15

\section{YEAR}

\section{7 patients}

- Explanted: 15

- Lost to follow up: 20

Appendix Fig 1. Follow up information about the study population.

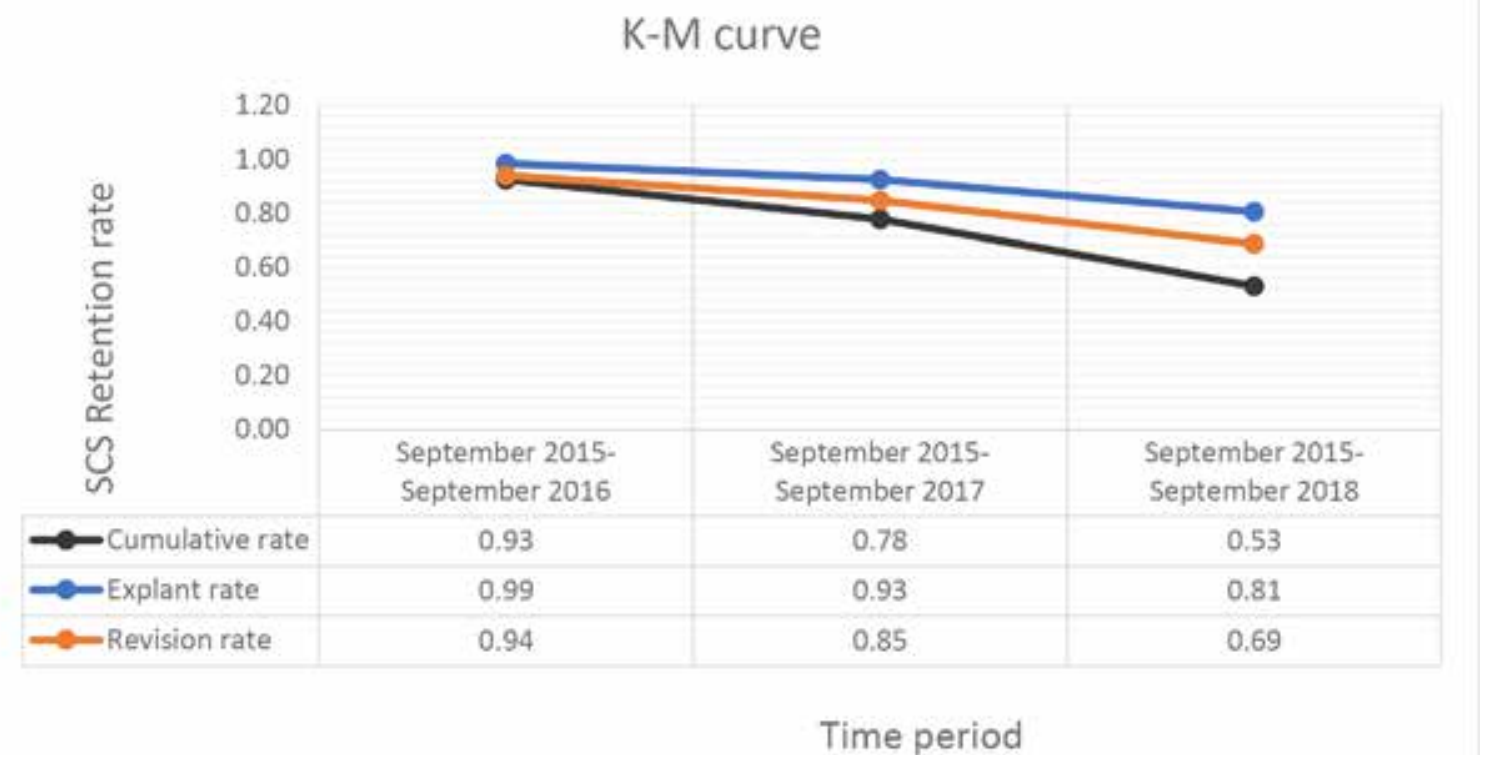

Appendix Fig 2. Correlation of revision and explants (as events) over time with Kaplan Meir graph. 
Appendix Table 1. Comparing mean percent pain relief at 1 month and 1 year within a sub-group.

\begin{tabular}{|c|c|c|c|c|}
\hline GROUP & Mean Pain \% relief at Trial & Mean Pain \% relief at 1 month & Mean Pain \% relief at 1 year & $P$ Value \\
\hline \multicolumn{5}{|l|}{ Therapy } \\
\hline $\operatorname{STD}(n=45)$ & 70 & 46 & 44 & 0.30 \\
\hline HF10 $(n=52)$ & 67 & 43 & 40 & 0.56 \\
\hline \multicolumn{5}{|l|}{ Gender } \\
\hline $\operatorname{Men}(n=48)$ & 67 & 44 & 38 & 0.02 \\
\hline Women $(n=49)$ & 70 & 44 & 43 & 0.99 \\
\hline \multicolumn{5}{|l|}{ Age } \\
\hline$\leq 55$ years $(n=46)$ & 70 & 44 & 39 & 0.24 \\
\hline$>55$ years $(n=51)$ & 68 & 43 & 41 & 0.58 \\
\hline \multicolumn{5}{|l|}{ BMI } \\
\hline Normal $(n=23)$ & 69 & 40 & 43 & 0.73 \\
\hline Overweight $(\mathrm{n}=33)$ & 68 & 43 & 44 & 0.69 \\
\hline Obese $(n=34)$ & 67 & 47 & 36 & 0.002 \\
\hline
\end{tabular}

Appendix Table 2. Comparing mean percent pain relief (PPR) over time between the sub-groups.

\begin{tabular}{|c|c|c|c|c|c|}
\hline GROUP & & Trial & 1 month & 6 months & 1 year \\
\hline \multicolumn{6}{|l|}{ Therapy } \\
\hline \multirow[t]{2}{*}{ HF10 SCS } & $\mathrm{n}$ & 73 & 70 & 61 & 52 \\
\hline & Mean PPR (SD) & $66.9(13.01)$ & $42.6(20.3)$ & $42(25.6)$ & $39.8(22.7)$ \\
\hline \multirow[t]{3}{*}{ STD SCS } & $\mathrm{n}$ & 59 & 58 & 52 & 45 \\
\hline & Mean PPR (SD) & $70(11.8)$ & $45.7(22.2)$ & $46.3(22.4)$ & 43.8 (27) \\
\hline & $P$ value & 0.15 & 0.43 & 0.35 & 0.45 \\
\hline \multicolumn{6}{|l|}{ Gender } \\
\hline \multirow[t]{2}{*}{ Men } & $\mathrm{n}$ & 62 & 62 & 56 & 48 \\
\hline & Mean PPR (SD) & $67.7(10.8)$ & $44.5(20.9)$ & $42.6(26.6)$ & $38.4(23.8)$ \\
\hline \multirow[t]{3}{*}{ Women } & $\mathrm{n}$ & 70 & 67 & 58 & 49 \\
\hline & Mean PPR (SD) & $68.8(13.4)$ & $42.9(22)$ & $44.6(22.2)$ & $43.2(26.6)$ \\
\hline & $P$ value & 0.6 & 0.69 & 0.67 & 0.36 \\
\hline \multicolumn{6}{|l|}{ Age } \\
\hline \multirow[t]{2}{*}{$\leq 55$ years } & $\mathrm{n}$ & 65 & 63 & 58 & 46 \\
\hline & Mean PPR (SD) & $69.8(10.8)$ & $45(23.5)$ & $46.6(27.5)$ & $42.6(26.5)$ \\
\hline \multirow[t]{3}{*}{$>55$ years } & $\mathrm{n}$ & 67 & 66 & 59 & 51 \\
\hline & Mean PPR (SD) & $66.8(13.3)$ & $41.1(19.3)$ & $43.5(23.9)$ & $43.7(28.1)$ \\
\hline & $P$ value & 0.16 & 0.49 & 0.52 & 0.84 \\
\hline \multicolumn{6}{|l|}{ BMI } \\
\hline \multirow[t]{2}{*}{ Normal } & $\mathrm{n}$ & 32 & 32 & 26 & 24 \\
\hline & Mean PPR (SD) & $69.1(11.8)$ & $40.09(23.7)$ & $46.6(26.0)$ & $43.3(26.7)$ \\
\hline \multirow[t]{2}{*}{ Overweight } & $\mathrm{n}$ & 46 & 44 & 39 & 33 \\
\hline & Mean PPR (SD) & $68.5(13.2)$ & $43.4(22.1)$ & $43.4(22.6)$ & $44(24.4)$ \\
\hline \multirow[t]{3}{*}{ Obese } & $\mathrm{n}$ & 44 & 44 & 40 & 34 \\
\hline & Mean PPR (SD) & $66.9(11.5)$ & $46.7(22.0)$ & $41.9(26.8)$ & $35.9(24.0)$ \\
\hline & $P$ value & 0.72 & 0.44 & 0.75 & 0.35 \\
\hline
\end{tabular}

